\title{
Factors affecting processing mode in visual search*
}

\author{
HOWARD EGETH, JANETTE ATKINSON $\dagger$, GROVER GILMORE, and NORMAN MARCUS \\ The Johns Hopkins University, Baltimore, Maryland 21218
}

\begin{abstract}
Visual search was studied under a variety of conditions to clarify some differences among the results of previous investigations and to provide a testing ground for models of visual information processing. Display configuration, target and field composition, exposure duration, and display size (up to 16 elements) were among the parameters investigated. In some conditions, mean reaction time was essentially invariant with display size, while in other conditions it increased substantially and linearly with display size. Current models of visual information processing were evaluated in the light of these and previous findings; all were found wanting. The data seem to demand a system subject to flexible cognitive control processes.
\end{abstract}

The processes underlying the responses of $\mathrm{Ss}$ to briefly presented displays have been the subject of many recent analyses. One of the central concerns of these analyses has been performance in visual detection tasks in which the $\mathbf{S}$ makes a simple response, such as a keypress, as soon as he detects some predefined aspect of the display. In the present paper, we shall be concerned with a type of detection task, visual search, in which the $S$ must indicate whether an array contains any of the elements of a previously memorized target set.1

Perhaps the most fundamental and characteristic finding of studies on visual search is that the time taken to detect the presence of a target element increases (usually linearly) with the number of elements (N) through which the $S$ must search. In the case of search through long columns of scrambled letters (e.g., Neisser, $1963,1967)$; it is hardly surprising that search time increases with the serial position of a target letter in a list. What is perhaps more surprising, and of greater theoretical significance, is that search time also increases with $\mathrm{N}$ for displays presented too briefly to allow an eye movement. There is general agreement that with such displays search time increases by at least $25 \mathrm{msec}$ for each element added to display (Atkinson, Holmgren, \& Juola, 1969, $25 \mathrm{msec} /$ element; Briggs \& Blaha, 1969, $60 \mathrm{msec} / \mathrm{element}{ }^{2}$; Burrows \& Murdock, 1969, $30 \mathrm{msec} /$ element early in practice; Estes \& Wessel, 1966, $27 \mathrm{~m} \mathrm{sec} /$ element; Holmgren, 1970, Experiment 1, $54 \mathrm{msec} /$ element; Sternberg, $1967,37 \mathrm{msec} /$ element). Such results have frequently been interpreted to mean that the elements of a display are processed serially, i.e., one after another. (For a more complete account of the

*This research was supported in part by a contract between the Engineering Psychology Programs, Office of Naval Research, and The Johns Hopkins University. The authors would like to thank Gerald Gardner, John Jonides, Edward Smith, and James Townsend for helpful suggestions on an earlier draft of this paper.

$\div$ Now at the Physiological Laboratory, University of Cambridge. theoretical issues involved in the interpretation of these results, the reader is referred to Egeth, Jonides, and Wall, 1972.)

A notable exception to the usual finding that mean reaction time (RT) increases substantially with $\mathrm{N}$ may be found in the series of experiments reported by Egeth, Jonides, and Wall. In their Experiment II, the target was the digit 4 and the nontargets were all Cs. When the target was absent, and thus the field contained nothing but Cs (from one to six), the mean RT did not increase with $\mathrm{N}$; indeed, the slope was $-0.2 \mathrm{msec} /$ element. When a target was present, the slope, although significantly different from zero, was only $6.3 \mathrm{msec} / \mathrm{element}$. More interesting are the results of Experiment IV of Egeth et al in which the target set was defined categorically as any digit while the nontarget set consisted of the letters of the alphabet. Early in practice, mean "absent" RT increased with $\mathrm{N}$, but by the fourth experimental session, the slope was insignificantly different from zero (4 msec/element). Mean "present" RT was not significantly related to $\mathrm{N}$ at any level of practice. These results were taken to mean that elements in the array to be searched could be analyzed by independent parallel channels (Gardner, in press).

It was the purpose of the present investigation to attempt to answer some questions raised by the findings of Egeth et al. In Experiment I, some miethodological factors that might be responsible for the differences between the findings of Egeth et al and those of previous investigators were examined. In Experiment II, arrays of up to 16 elements were used in the digit/letter paradigm in an attempt to determine the upper limit for parallel processing. The effects of practice and exposure duration on processing were also examined. Finally, in the discussion section, an attempt is made to evaluate current theoretical positions in the light of evidence from these studies and previous experiments.

\section{EXPERIMENT I}

In the previous studies showing mean RT to be a 


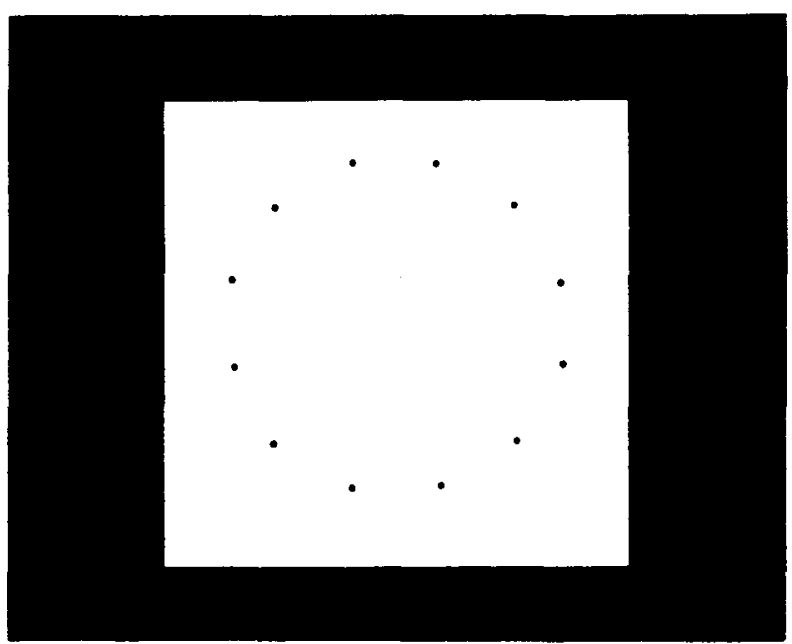

Fig. 1. Loci used for placement of stimulus elements. No dots were present on actual stimulus cards.

linearly increasing function of $\mathrm{N}$, horizontal displays centered at the fixation point with equal spacing between elements were utilized. Thus, overall visual angle increased and average acuity decreased as $\mathrm{N}$ was increased. Also. such displays may have induced a left-to-right serial scanning strategy because of their similarity to printed words. Finally. if elements were close. there would be some increase in lateral masking between adjacent elements as $\mathrm{N}$ increased. All of the foregoing factors might have tended to lengthen RT as $\mathrm{N}$ increased. By contrast. Egeth et al spread their elements randomly on a circle. $3.4 \mathrm{deg}$ in diam. with the restriction that when $N$ was two or more. at least two elements of the array were separated by the diameter of the circle. Under these conditions. it is unlikely that acuity. scanning strategies, or lateral masking would be important determinants of performance. To determine the importance of the spatial arrangement of elements within displays. Experiment I included a direct comparison of performance on linear vs "circular" arrays.

In this experiment. single-element target sets were used. For different groups of Ss. the target was either a 4 or an $\mathrm{A}$; for half of each group. the nontargets were letters, and for the other half, digits. It should be instructive to see if letters and digits are searched through at the same speed and if a categorical difference between target and nontarget elements aids search even though the target is single and fixed for a particular $S$.

The use of a constant target deserves some discussion. Egeth et al suggested that the trial-by-trial composition of the target and nontarget sets might be an important determinant of search performance. In their studies. the target and nontarget elements ( 4 vs $C$ : digits vs letters) were constant for a particular S: i.e.. they only had to be defined once at the beginning of the experiment. Thus, their targets and nontargets formed mutually exclusive and easily remembered sets. However. this was not the case in the previous studies in which mean RT increased substantially with $\mathbb{N}$. It has been common for a stimulus to serve as a target in one condition and then as a nontarget in another condition. ${ }^{3}$ In the present experiments, we have used only the constant-target procedure, and have not attempted to compare the constant-and variable-target set procedures directly.

\section{Method}

\section{Subjects}

Thirty-two right-handed male students at The Johns Hopkins Liniversity served as paid volunteers. Each served in a single session lasting approximately $50 \mathrm{~min}$. All had normal or corrected to normal visual acuity.

\section{Design}

Half of the Ss searched for the letter $A$ and the other half for the digit 4 , these targets being selected because of their physical similarity. For half of each of these two groups, the nontarget elements were random digits, and for the other half. random letters. All Ss performed under two display conditions, linear and circular. described below. Half of the Ss received the linear displays first: the other half received the circular displays first.

Each S was instructed to respond by pressing a telegraph key with his right index finger as soon as he detected a target item. and to refrain from responding when no target item was presented. Thus. the data collected in this experiment are from "present" responses. not "absent" responses.

\section{Stimuli}

The stimulus elements were Prestype 24-pt black Futura Demi numerals and uppercase letters. subtending a visual angle of $.3 \mathrm{deg}$ in height and with a stroke width of $.06 \mathrm{deg}$. They were mounted on cards within a $76 \times 76 \mathrm{~mm}$ white area. The number of elements on a card varied from one to five.

The linear displays were always centered at the fixation point. and the center-to-center distance between adjacent elements was $.9 \mathrm{deg}$. To construct the circular displays. the configuration shown in Fig. I was used. Stimuli appeared equally of ten at the 12 locations. When only one element was present. it was randomly located at one of the loci. When two elements were present. they were located at diametrically opposed loci $13.6 \mathrm{deg}$ center-to-center distance). When three elements were presented. two (including the target when a target was present) were at diametrically opposed loci. while the third location was selected randomly from the remaining positions. Similar procedures were used for four- and five-element trials. To aroid crowding. the use of three adjacent loci was not permitted. When such a sequence occurred. one of the elements was relocated randomly. In the linear configuration. the edge-to-edge separation of adjacent letters could be as small as $.53 \mathrm{deg}$. Whereas with the circular arrangement. the smallest separation between letters was 1.37 des. Thus. substantial lateral masking would be expected in the former case. Whereas little or no masking would be expocted in the latter case (Gardner. 1970. pp. 29-30).

A separate deck of 80 timulus card fplus sereral pratice cards) was prepared for cach of the eight combination of tarests 
(A and 4), nontargets, and displays (circular and linear). In each of these decks. there were 16 cards prepared for each value of $\mathrm{N}$ (1. 2. 3. 4. 5). At each level of $N$, half of the cards contained a target and half did not. Moreover, targets appeared at all possible stimulus locations approximately equally of ten (as equally as could be realized, given the other constraints). An effort was made to keep the eight decks as comparable as possible. For example. consider a card in the condition in which the target was $A$, digits served as nontargets, and the array was linear. In each of the other conditions, there was a particular card that matched our hypothetical exemplar as closely as possible. Thus, the following represent a set of "matching" cards for $N=4$ in the linear condition (E L 4 Q; E L A Q;2943;29 A 3). This set of four cards was completed by four more in the circular configuration using the same stimulus elements, but of course there was no way to match locations of elements between the linear and circular configurations.

\section{Procedure}

Stimulus cards were presented for $150 \mathrm{msec}$ in a Scientific Prototype two-channel tachistoscope at a viewing distance of $84 \mathrm{~cm}$. Between trials, a small black fixation point on a white background indicated the center of the visual field. One second before stimulus presentation, $S$ s were alerted with a verbal "ready" signal. The intertrial interval was approximately 5 sec. Stimuli were presented in a different random order for each $S$.

Ss were given 10 practice trials before being presented with an 80 -trial test series in a given display configuration. There was a short break after completing the test series, and then Ss were shifted to the other display configuration, 10 practice trials being given before the new 80 -trial test series.

Response latency was measured from the onset of the stimulus to the depression of a response button with the thumb of the preferred hand.

Ss were instructed to "... respond as quickly as possible, without sacrificing accuracy." No feedback was provided about response speed, however they were informed whenever they made an error. Since errors tend to be disruptive in a reaction-time task, whenever an error was made, one of the practice cards was presented on the following trial. Data were not collected on the trial following an error.

\section{Results}

In Fig. 2, mean RT for correct responses is plotted as a function of $\mathbf{N}$ for each of the eight combinations of the $\mathrm{A}$ and 4 targets, the digit and letter nontargets, and the circular and linear display patterns. Error data appear in Table 1.

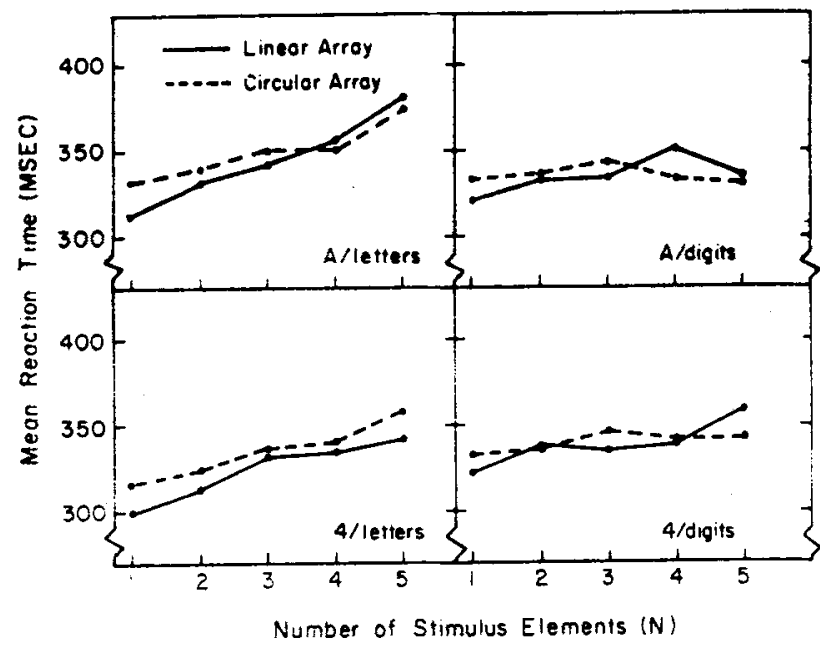

Fig. 2. Mean reaction time for correct responses as a function of number of stimulus elements: Experiment $I$.

To evaluate the statistical significance of the effects of these variables and their interactions on reaction time, the slope and intercept of the best-fitting straight line was calculated for each S's data in every condition. These slopes and intercepts were then cast in two separate four-way analyses of variance in which $A$ vs 4 , digit vs letter nontargets, and order (circle then line vs line then circle) were between-Ss factors and circle vs line was a within-Ss factor.

The mean slope for the circular arrays was $5.4 \mathrm{msec} / \mathrm{element}$, while the mean slope for the linear arrays was $10.7 \mathrm{msec} / \mathrm{element}$. The difference between these means was significant $[F(1,24)=9.53, p<.01]$. The identity of the nontargets was also significant, with the mean slope for search through letters $11.2 \mathrm{msec} /$ element and through digits $4.8 \mathrm{msec} / \mathrm{element}$ $[F(1,24)=6.53, p<.05]$. No other main effects or interactions even approached significance.

The data for the circular arrays were analyzed in further detail. Specifically, separate $t$ tests were performed for those Ss who searched through letters and

Table 1

Mean Error Proportions (Misses and False Positives) Averaged Over Ss

\begin{tabular}{|c|c|c|c|c|c|c|c|c|c|c|c|}
\hline \multirow[b]{3}{*}{ Condition } & \multirow[b]{3}{*}{ Array } & \multicolumn{10}{|c|}{ Number of Elements in Display } \\
\hline & & \multicolumn{2}{|c|}{1} & \multicolumn{2}{|c|}{2} & \multicolumn{2}{|c|}{3} & \multicolumn{2}{|c|}{4} & \multicolumn{2}{|c|}{5} \\
\hline & & $\mathbf{M}$ & FP & $\mathbf{M}$ & $\mathrm{FP}$ & $\mathbf{M}$ & FP & $\mathbf{M}$ & FP & $\mathbf{M}$ & FP \\
\hline A/Digits & $\begin{array}{l}\text { Horizontal } \\
\text { Circle }\end{array}$ & $\begin{array}{c}.016 \\
0\end{array}$ & $\begin{array}{c}.016 \\
0\end{array}$ & $\begin{array}{l}0 \\
0\end{array}$ & $\begin{array}{l}.063 \\
.094\end{array}$ & $\begin{array}{l}0 \\
0\end{array}$ & $\begin{array}{l}.094 \\
.078\end{array}$ & $\begin{array}{c}.031 \\
0\end{array}$ & $\begin{array}{l}.125 \\
.063\end{array}$ & $\begin{array}{c}0 \\
.094\end{array}$ & $\begin{array}{l}.047 \\
.125\end{array}$ \\
\hline A/Letters & $\begin{array}{l}\text { Horizontal } \\
\text { Circle }\end{array}$ & $\begin{array}{l}0 \\
0\end{array}$ & $\begin{array}{l}0 \\
0\end{array}$ & $\begin{array}{l}0 \\
0\end{array}$ & $\begin{array}{l}.016 \\
.047\end{array}$ & $\begin{array}{c}0 \\
.016\end{array}$ & $\begin{array}{l}.063 \\
.109\end{array}$ & $\begin{array}{c}0 \\
.016\end{array}$ & $\begin{array}{l}.109 \\
.125\end{array}$ & $\begin{array}{c}0 \\
.016\end{array}$ & $\begin{array}{l}.078 \\
.078\end{array}$ \\
\hline $4 / D$ igits & $\begin{array}{l}\text { Horizontal } \\
\text { Circle }\end{array}$ & $\begin{array}{l}0 \\
0\end{array}$ & $\begin{array}{l}0 \\
0\end{array}$ & $\begin{array}{l}0 \\
0\end{array}$ & $\begin{array}{l}.031 \\
.016\end{array}$ & $\begin{array}{l}.016 \\
.016\end{array}$ & $\begin{array}{l}.031 \\
.031\end{array}$ & $\begin{array}{c}.016 \\
0\end{array}$ & $\begin{array}{l}.094 \\
.109\end{array}$ & $\begin{array}{l}.016 \\
.094\end{array}$ & $\begin{array}{l}.016 \\
.047\end{array}$ \\
\hline 4/Letters & $\begin{array}{l}\text { Horizontal } \\
\text { Circle }\end{array}$ & $\begin{array}{l}0 \\
0\end{array}$ & $\begin{array}{c}0 \\
.016\end{array}$ & $\begin{array}{l}0 \\
0\end{array}$ & $\begin{array}{l}.109 \\
.125\end{array}$ & $\begin{array}{l}0 \\
0\end{array}$ & $\begin{array}{l}.031 \\
.141\end{array}$ & $\begin{array}{l}0 \\
0\end{array}$ & $\begin{array}{l}.109 \\
.141\end{array}$ & $\begin{array}{l}0 \\
0\end{array}$ & $\begin{array}{l}.109 \\
.094\end{array}$ \\
\hline
\end{tabular}


those who searched through digits. to determine if their slopes were significantly different from zero. For the 16 Ss who searched through letters, the mean slope was $8.9 \mathrm{msec} / \mathrm{element}$ on the circular arrays $(\mathrm{t}=5.1$, $\mathrm{p}<.01$ ). however, for the 16 Ss who searched through digits, the mean slope was only $1.9 \mathrm{msec} / \mathrm{element}$ $(t>1)$. Neither of these results was affected by target identity (A or 4). Thus, not only can we assert that circular arrays lead to shallower slopes than do linear arrays, but that there are conditions under which such slopes do not differ reliably from zero.

The difference in search rates between letter and digit nontarget backgrounds is highly suggestive. These data may mean that the larger population of letters produces greater average interelement perceptual similarity, thus making classification of an element more difficult than with the smaller population of number nontargets. However, since only $\mathrm{A}$ and 4 were used as targets in the present experiment, it is premature to speculate as to whether the effect we have observed here is a general one.

Perhaps the most important result of Experiment I is that the display configuration does, indeed, significantly affect the rate of search. Although this experiment was not designed to pinpoint just what aspect of the linear display results in a slowed rate of search, the overall effect is clear. However, we cannot fail to note that our search rates, even with linear displays, are faster than those previously reported for early stages of practice (except for Egeth, Jonides, and Wall, 1972) averaging $10 \mathrm{msec} /$ element vs about $25 \mathrm{msec} /$ element as a typical "fast" search rate in earlier research. Thus, despite the fact that display arrangement did make a significant difference in the slope of the function relating mean RT to $\mathrm{N}$, it is clear that this factor cannot be solely responsible for the difference between the results of Egeth et al and previous investigators.

For intercepts, the only important effect was that due to displays. The linear arrays resulted in a mean intercept of $305 \mathrm{msec}$, while the mean for the circular arrays was $324 \mathrm{msec}[\mathrm{F}(1,24)=17.68, \mathrm{p}<.01]$. The effect of digit $(324 \mathrm{msec})$ vs letter $(305 \mathrm{msec})$ nontargets was not quite significant $[F(1.24)=4.21, p>.05]$. Note that the former is a within-Ss comparison while the latter is between Ss. In conjunction with the slope analysis, the intercept analysis makes it clear that small displays are handled more quickly in the linear than in the circular mode. Clearly with. say, one or two elements present, under the linear condition the elements are presented with less spatial uncertainty and in a region of higher acuity than is the case for the circular arrays.

\section{Errors}

It is clear from Table 1 that there is a tendency for errors to increase with $N$. even in those conditions in which mean RT does not increase substantially with $\mathrm{X}$.
Thus, it is possible that the flatness of these functions is produced in part by a speed-accuracy tradeoff. While this interpretation of the present findings cannot be lightly dismissed, it is worth noting that an increase in error rate with $N$ may be expected even on an independent parallei channels model (Eriksen \& Spencer. 1969). The reason, in brief, is that deciding whether or not a target is represented among multiple channels may involve a different decision process than when a single channel is involved. This point may be seen most clearly by considering false positive rates for a presence responder. If input channels are independent and mean RT the same as for $N=1$, the probability of a false positive should be given by $1-\left(1-p_{f}\right)^{N}$, where $p_{f}$ is the false positive rate for $\mathrm{N}=1$. If we assume, for the purpose of exposition, a false positive rate of .01 when $\mathrm{N}=1$, then, when $\mathrm{N}=5$, the false positive rate should be $1-.99^{5}$, or about .05 .

\section{Extension}

A brief follow-up experiment was conducted to determine whether our use of a go/no-go response might have given rise to data different from that obtained by means of the more traditional two-choice response (see. e.g.. Egeth. Marcus, \& Bevan, 1972). The condition selected for study was search for A among letters in linear displays. The data from the four Ss who had already served in this condition (and who had received the linear displays before the circular displays) were supplemented by data from two additional Ss. Six new Ss served in a two-choice version of the same task, each responding with his preferred (right) hand when a target was present and with his left hand when no target was present. As in the previous experiment. 10 practice trials were given before the 80-trial test series. However. since the response assignments in a two-response task might be more difficult to master than in a one-response task. Ss were given a second block of 80 trials with the same cards in a shuffled order.

Slopes and intercepts were calculated for individual Ss, and a comparison of the slopes for "present" responses obtained under the one-response condition (17.8 msec/element) and the first block of the two-response condition $(21.3 \mathrm{msec} / \mathrm{element})$ failed to indicate a significant difference $[t(10)=.27 . p>.05]$ For the second block of trials in the two-response task. the mean slope was $19.4 \mathrm{msec} / \mathrm{element}$. Thus, there is little reason to believe that our choice of response mode seriously affected the data obtained in the main experiment.

\section{EXPERIMENT II}

\section{Method and Procedure}

The $S$ is tusk was to respond as quickly as possible when at target was present in an atray. The turget set consisted of the 
digits 2-9 inclusive. while nontargets were selected from among the uppercase letters of the alphabet. excluding B, D. I, O, and S. These letters and the digits 1 and 0 were excluded because of their high visual confusability with other characters. All digits and letters (uppercase) were produced on a typewriter with a large typeface so that each element subtended $0.35 \mathrm{deg}$ in height and 0.20 deg across. The arrays were circular, as in Experiment I, but only 8 equidistant loci, rather than 12 , were used in constructing the stimuli. When a specific locus was used, a pair of elements (either two letters or a letter and a digit) were shown in that area, one to the left and one to the right of the locus (the separation between letters being approximately $.1 \mathrm{deg}$ ). The nearest edge of any element to the fixation point was $2.0 \mathrm{deg}$. Since interelement spatial separation at each location of the array was constant and since the separation between elements from different locations exceeded $1 \mathrm{deg}$, masking effects should be unrelated to $\mathrm{N}$ (cf. Gardner, 1970). Since pairs of elements were used at each location. array size could be $2,4,6,8,10,14$, or 16 elements. there being eight cards for each array size containing a digit (each possible digit occurring once per set size) and eight cards without a digit. There was never more than a single digit on a card, and the location of a particular digit was balanced across array sizes.

\section{Subjects}

Twenty new volunteers, students at The Johns Hopkins University, were paid $\$ 1.50$ for each experimental session lasting between 20 and $45 \mathrm{~min}$. Each $S$ attended four sessions, one each day, at approximately the same time for 4 consecutive days. All had normal or corrected to normal visual acuity. The Ss were in three groups: (1) 2-16/500-Four Ss were presented all cards for all array sizes $(2,4,6,8,10,12.14$, and 16), each card being exposed for $500 \mathrm{msec}$. (2) 2-8/500-Six Ss were presented array sizes 2, 4, 6, and 8. exposure duration being $500 \mathrm{msec}$. (3) $2-8 / 200-\mathrm{Six}$ Ss were presented the same array sizes as Group 2, but with exposure duration of $200 \mathrm{msec}$.

All cards were viewed in a Scientific Prototype two-channel tachistoscope at a viewing distance of $84 \mathrm{~cm}$. Each card was preceded by a white field containing a fixation point.

Each $S$ had an initial practice series of 20 randomly selected cards before each test series. In the test series, the cards were arranged in random order, which was the same for all $S_{s}$ in a particular group and identical for all Ss in Groups 2 and 3 . The test sessions were twice as long for the $S s$ in 2-16/500 as those in $2-8 / 500$ and $2-8 / 200$ because of the inclusion of the larger array sizes. Consequently, the $S$ s in $2-16 / 500$ were given a break in the middle of their test session and five practice cards (randomly selected) before the start of the second half of each session.

\section{Results and Discussion}

Mean RT for correct responses as a function of $\mathrm{N}$ for each day of practice is shown in Fig. 3, and error data are given in Table 2. It appears that the slope of the function relating mean $\mathrm{RT}$ to $\mathrm{N}$ decreases steadily with practice in all groups. However, inspection of the data of individual Ss indicated that the group data are somewhat misleading. Therefore, slopes were calculated for each $\mathrm{S}$ on each day of practice, and these slopes are shown in Fig. 4. It is evident in this figure that for the 2-16/500 condition, slopes for three of the four Ss declined to essentially zero by the fourth day of practice. For the $2-8 / 200$ condition. the slopes for all six Ss were very low on the fourth day of practice $($ mean $=.5 \mathrm{msec} /$ element $)$, not differing significantly from zero $(t<1)$ for the group as a whole. Interestingly, in the $2.8 / 500$ group,

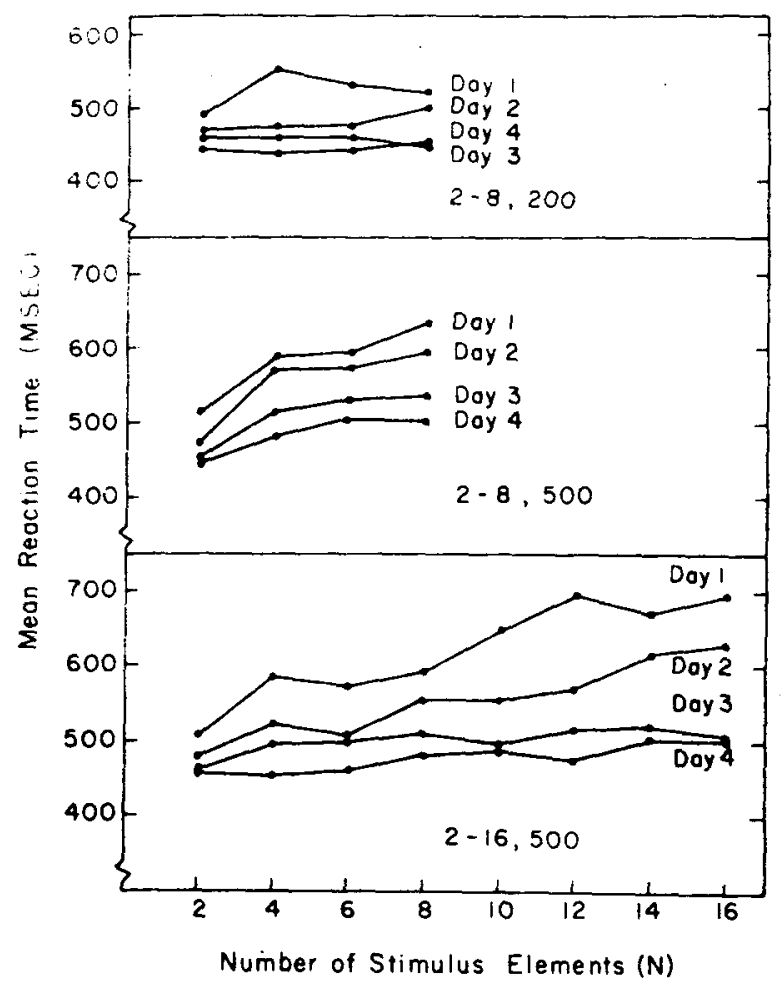

Fig. 3. Mean reaction time for correct responses on each day of practice as a function of number of stimulus elements: Experiment II.

the slopes for three Ss behaved in essentially the same way as the slopes for Ss in the 2-8/200 group; however, for the other three $S s$, slopes did not decline with practice.

It is possible that the difference in performance between the 200- and $500-\mathrm{msec}$ groups is one of strategy. For example, some of the Ss with the longer exposure duration may use the extra time to "check" their answers before initiating a response, resulting in a longer latency and higher accuracy on such trials. We do not envisage this type of strategy as a truly serial scan; instead, we assume that the $\mathrm{S}$ merely makes an eye movement during the $500-\mathrm{msec}$ exposure duration and places part of the display where the digit may be in foveal rather than parafoveal vision. In this way, he adds the time for the initiation of an eye movement to his RT. To assess the plausibility of this view, an analysis was made of errors and long reaction times. A long reaction time was taken to be an RT that exceeded the median RT for a particular display size by $200 \mathrm{msec}$, where $200 \mathrm{msec}$ was an approximation of the initiation time for an eye movement. The number of errors (missed digits) and the number of long RTs for each group at each display size are shown in Table 3. It can be seen from this table that the $2-8 / 500$ group has both more long RTs ( 54 vs 0 ) and fewer misses (42 vs 106) than the 2-8/200 group, a result consistent with the 
Table 2

Mean Error Proportions (Misses and False Positives) Averaged Over Ss

\begin{tabular}{|c|c|c|c|c|c|c|c|c|c|c|c|c|c|c|c|c|}
\hline \multirow[b]{3}{*}{ Day } & \multicolumn{16}{|c|}{$\begin{array}{c}\text { Group } 2-16,500 \\
\text { Array Size }\end{array}$} \\
\hline & \multicolumn{2}{|c|}{2} & \multicolumn{2}{|c|}{4} & \multicolumn{2}{|c|}{6} & \multicolumn{2}{|c|}{8} & \multicolumn{2}{|c|}{10} & \multicolumn{2}{|c|}{12} & \multicolumn{2}{|c|}{14} & \multicolumn{2}{|c|}{16} \\
\hline & $\mathrm{M}$ & $\mathrm{FP}$ & $\mathrm{M}$ & $\mathrm{FP}$ & $\mathrm{M}$ & FP & MI & FP & $\mathbf{M}$ & $\mathrm{FP}$ & M & FP & $M$ & FP & $M$ & FP \\
\hline 1 & .000 & .000 & .000 & .000 & .125 & .000 & .188 & .094 & .156 & .094 & .313 & .094 & .250 & .156 & .156 & .094 \\
\hline 2 & .000 & .000 & .000 & .000 & .063 & .000 & .125 & .031 & .188 & .125 & .156 & .156 & .125 & .063 & .188 & .156 \\
\hline 3 & .000 & .000 & .000 & .000 & .000 & .000 & .031 & .031 & .094 & .125 & .125 & .188 & .219 & .156 & .219 & .094 \\
\hline \multirow[t]{3}{*}{4} & .000 & .000 & .000 & .000 & .000 & .000 & .031 & .000 & .094 & .094 & .063 & .156 & .000 & .125 & .219 & .094 \\
\hline & \multicolumn{8}{|c|}{$\begin{array}{c}\text { Group } 2-8,200 \\
\text { Array Size }\end{array}$} & \multicolumn{8}{|c|}{$\begin{array}{c}\text { Group } 2-8,500 \\
\text { Array Size }\end{array}$} \\
\hline & \multicolumn{2}{|c|}{2} & \multicolumn{2}{|c|}{4} & \multicolumn{2}{|c|}{6} & \multicolumn{2}{|c|}{8} & \multicolumn{2}{|c|}{2} & \multicolumn{2}{|c|}{4} & \multicolumn{2}{|c|}{6} & \multicolumn{2}{|c|}{8} \\
\hline Day & II & FP & $\mathrm{M}$ & $\mathrm{FP}$ & $\mathrm{MI}$ & FP & $\mathrm{MI}$ & FP & $\mathbf{M}$ & FP & $\mathrm{M}$ & FP & $\mathrm{M}$ & FP & $\mathrm{M}$ & FP \\
\hline 1 & .021 & .000 & .167 & .062 & .271 & .167 & .271 & .292 & .000 & .000 & .000 & .000 & .167 & .083 & .271 & .125 \\
\hline 2 & .000 & .000 & .083 & .042 & .208 & .125 & .250 & .208 & .000 & .000 & .000 & .000 & .125 & .062 & .146 & .146 \\
\hline 3 & .000 & .000 & .062 & .062 & .167 & .185 & .229 & .125 & .000 & .000 & .021 & .000 & .042 & .083 & .062 & .104 \\
\hline 4 & .000 & .000 & .000 & .021 & .125 & .125 & .167 & .125 & .000 & .000 & .000 & .021 & .021 & .021 & .042 & .083 \\
\hline
\end{tabular}

hypothesized strategic difference between the groups.

On the basis of these results. especially those indicating near-zero slopes for mean RT as a function of $\mathrm{N}$, we might conclude that after practice at least 16 independent channels are available for the detection of a digit in a field of letters. However. the increase in error rate with increases in $N$ does not seem compatible with

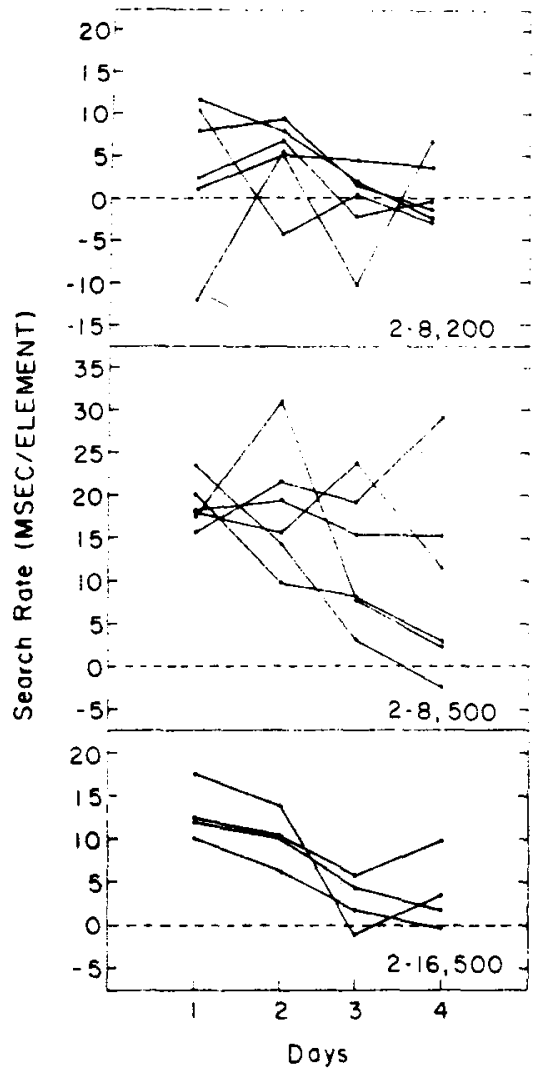

Fig. 4. Search rate as a function of practice for individual Ss. an unembellished independent channels model. As may be seen in Table 2, the false positive rate is essentially zero for small values of $\mathrm{N}$, but increases to about $11 \%$ for $N=16$. Clearly, the formula $1-\left(1-p_{f}\right)^{N}$ does not correctly predict the growth in false positives under these circumstances.

\section{GENERAL DISCUSSION}

In this section, we shall briefly describe some of the models that have been advanced to account for performance in detection experiments of the search variety, and we shall attempt to evaluate these models in the light of accumulated evidence.

\section{Serial Models}

The distinguishing characteristic of a serial model is that elements in a visual array are compared one after another with the elements of the target set (whether the target set is itself examined serially or all at once is a separate issue). Clearly. such a model predicts that RT will increase linearly with $\mathrm{N}$. This kind of model fails to account for the invariance of RT with changes in $\mathrm{N}$. a result that has now been obtained in several experiments on visual search (e.g. some conditions of the present research and the research of Egeth et al. 1972: Estes. 1972). Evidence contrary to a serial model has also been obtained in search experiments in which stimuli are presented tachistoscopically and the performance measure is accuracy rather than latency. Gardner (in press) has found that when the target and nontarget elements are highly distinctive. accuracy is independent of $\mathrm{N}$.

A serial model also has difficulty accounting for the results of same-different discrimination. a paradigm closely related to search. An array of elements is presented. and the $\mathrm{S}$ indicates whether the elements alo 
Table 3

Frequency of Misses (M) and Long Reaction Times (LRT)

\begin{tabular}{|c|c|c|c|c|c|c|c|c|c|c|c|c|c|c|c|c|}
\hline \multirow[b]{3}{*}{ Ss } & \multicolumn{8}{|c|}{$\begin{array}{c}\text { Group } 2-8,200 \\
\text { Array Size }\end{array}$} & \multicolumn{8}{|c|}{$\begin{array}{c}\text { Group } 2-8,500 \\
\text { Array Size } \\
\end{array}$} \\
\hline & \multicolumn{2}{|r|}{2} & \multicolumn{2}{|c|}{4} & \multicolumn{2}{|c|}{6} & \multicolumn{2}{|c|}{8} & \multicolumn{2}{|c|}{2} & \multicolumn{2}{|c|}{4} & \multicolumn{2}{|c|}{6} & \multicolumn{2}{|r|}{8} \\
\hline & II & LRT & $\mathbf{M}$ & LRT & $\mathbf{M}$ & LRT & $\mathrm{M}$ & LRT & M & LRT & $\mathrm{M}$ & LRT & $\mathbf{M}$ & LRT & M & LRT \\
\hline 1 & 0 & 0 & 2 & 0 & 6 & 0 & 2 & 0 & 0 & 0 & 0 & 1 & 3 & 0 & 2 & 2 \\
\hline 2 & 0 & 0 & 3 & 0 & 10 & 0 & 14 & 0 & 0 & 0 & 0 & 5 & 3 & 1 & 6 & 2 \\
\hline 3 & 0 & 0 & 0 & 0 & 2 & 0 & 5 & 0 & 0 & 1 & 0 & 6 & 4 & 8 & 3 & 8 \\
\hline 4. & 0 & 0 & 2 & 0 & 5 & 0 & 4 & 0 & 0 & 0 & 0 & 1 & 4 & 3 & 5 & 3 \\
\hline 5 & 1 & 0 & 6 & 0 & 6 & 0 & 9 & 0 & 0 & 0 & 1 & 3 & 1 & 1 & 3 & 3 \\
\hline 6 & 0 & 0 & 2 & 0 & 8 & 0 & 10 & 0 & 0 & 0 & 0 & 1 & 1 & 2 & 6 & 3 \\
\hline Total & 1 & 0 & 14 & 0 & 37 & 0 & 54 & 0 & 0 & 1 & 1 & 17 & 16 & 15 & 25 & 21 \\
\hline
\end{tabular}

all identical to one another or whether there is (at least) one discrepant element among the others. Several studies have shown that response latencies in this task are independent of $N$ (e.g., Connor, 1971; Donderi \& Case, 1970; Donderi \& Zelnicker, 1969; Egeth, Jonides, \& Wall, 1972, Experiment I). In these studies, error rates have also been independent of $\mathrm{N}$, which was not the case in some of the search experiments cited. Thus, it is unlikely that the results from the same-different paradigm were the result of a speed-accuracy tradeoff.

\section{Limited-Capacity Parallel Models}

Rumelhart (1970) has proposed a model in which information concerning critical features of display elements is extracted in parallel from all of the elements in the display. It is further assumed that the feature-extraction system is limited in capacity (e.g., to $\mathrm{k}$ features per unit of time). Thus, the greater the number of elements in the display, the fewer the features, on the average, that may be extracted per unit of time from any given element and thus the longer the response latency.

Clearly, the evidence presented in the preceding section concerning the invariance of RT and/or accuracy with changes in $\mathrm{N}$ also suffices to reject this kind of limited-capacity parallel model.

Furthermore, Estes (1972) has pointed out that both the serial model and the limited-capacity parallel model proposed by Rumelhart are inconsistent with the finding that latency of correct responses, when corrected for guessing, is independent of the number of redundant target elements (Bjork \& Estes, 1972; Wolford, Wessel, \& Estes, 1968). In the case of the serial model, this is because with redundant targets a target should be detected sooner, on the average, than when there is only a single target element. In the case of the parallel model, the criterion number of features should be extracted sooner when there are redundant targets than when there is only one.

\section{Independent Parallel Channels Model}

If elements are spaced far enough apart to avoid perceptual interaction (e.g., Collins \& Eriksen, 1967), then each is assumed to be processed by an independent channel. This model was first used to describe results in a detection experiment by Eriksen and Spencer (1969) and has since been elaborated by Gardner (in press).

Since each element has its own channel, there is no reason for mean RT to increase as the number of elements increases, and thus this model is consistent with data showing RT to be independent of $N$. This same property permits the model to predict that correct RT should be independent of the number of redundant target elements (e.g., Bjork \& Estes, 1972). However, by the same token, the independent channels notion would seem to be inconsistent with RT increasing substantially with $\mathrm{N}$, as, for example, in the present Experiment $\mathrm{I}$, searching for an $\mathrm{A}$ among letters in a linear array. ${ }^{4}$ The model would also seem to be inconsistent with the rate of increase in errors with increases of $\mathrm{N}$ found in the present Experiment II. However, one could perhaps claim that the pattern of errors reflects a limit in the capacity of a postperceptual mechanism that holds perceptually processed material while a decision process operates on it.

Although we are led to reject the independent parallel channels model, it should be pointed out that we are rejecting only a particular version of that model, specifically a version in which the latency for completion of postperceptual decisional processing is independent of the number of perceptual channels (Gardner, in press). However, it may be possible to develop an independent parallel channels model in which decisional processing time is, under some circumstances, dependent on $\mathbf{N}$. The characterization of such decision rules should be an important task for future theoretical speculation.

\section{Interactive Channels Model}

Estes (1972) has proposed a model that shares with Rumelhart's the assumption of a set of feature detectors. Corresponding to each feature detector is a set of input channels distributed over the visual field, with density decreasing from the fovea. If, upon exposure of a display, the set of detectors activated by inputs from 
any one display location matches the memorial representation of a target element, a "primary detection response" is evoked and processing terminates. Primary detection responses are assumed to be accurate and of a uniformly low latency. It is also possible for a target to be present without a primary detection response occurring. This might happen if neighboring elements are present that share features with the target element, thus preempting essential input channels. When no primary detection response occurs, feature extraction continues until terminated by either a postexposure mask or temporal decay. If a match is found at this time, a response is made; if no match is found, a response is made at random. Clearly. either of these outcomes will result in a reaction time longer than that of a primary detection response.

The overall mean reaction time and proportion of correct responses in a specific condition is a function of the mix of primary detection responses and "secondary" responses. This mix in turn depends upon several factors, the most important being target-nontarget confusability. Indeed, this model was generated specifically to account for the effects of target-nontarget confusability found by Estes. For example, when nontargets were identical to one another (filled-in 5 by 6 dot matrices) and not at all confusable with the target(s) (letters formed from dots within the 5 by 6 matrices). RT was essentially unrelated to $\mathrm{N}$. However, when nontargets were a random set of letters. RT increased substantially with $\mathrm{N}$.

Estes's model is perhaps the most complete and powerful yet advanced to account for the findings of visual detection studies. Nevertheless. it founders on at least three points.

First, mean RT has been shown to be invariant with $\mathrm{N}$ under conditions where nontargets were not homogeneous and thus where some degree of target-nontarget confusability would be expected following Estes's reasoning. This has been demonstrated by Egeth et al (1972) as well as in the present research.

Second. Gordon (1968) has Ss search for and cancel a target element ( $\mathrm{T}$ ) whenever it occurred in a list consisting of the nontarget element $N_{1}$. Ss also searched for $\mathrm{T} s$ in a list consisting of the nontarget element $\mathrm{N}_{2}$. In another condition, $\mathrm{S}$ s searched for $\mathrm{T}$ in a list consisting of a random pattern of $\mathrm{N}_{1}$ and $\mathrm{N}_{2}$ elements. Search time was slower here than in the slower of the two homogeneous lists. In other words. nontarget heterogeneity per se reduced the speed of visual search. The interactive channels model makes no provision for this result, since target-nontarget confusability is not any higher in the heterogeneous list than in the homogeneous list.

Third, even with target-nontarget confusability perfectly controlled, the nature of the function relating mean RT to $N$ can be radically altered by the nature of a S's "mental set." One example of this comes from a study by Jonides and Gleitman (1972). Consider a set of stimuli. each of which contains the target element
"O": O: BO; EOT: EOPX: ANOPR; CGHLMO. The preceding represent stimuli for $\mathbf{N}=1$ to $\mathrm{N}=6$; elements were presented in the "circular" arrays used in the present Experiment I. For Ss who were led to believe that the target was the letter "O," the slope of the function relating mean $\mathrm{RT}$ to $\mathrm{N}$ was about $30 \mathrm{msec} /$ lement; however. for $\mathrm{Ss}$ who were led to believe that the target was the digit 0 , the function was essentially flat. Note that this difference in results obtained even though the stimulus elements were physically identical for the two groups of Ss. (This suggests that the results obtained in the usual digit-letter search paradigm are not simply due to digits and letters being composed of different sets of distinctive features.)

What these three points suggest is the need for a model that permits the $\mathrm{S}$ greater cognitive flexibility than has heretofore been the case. In the terminology of Atkinson and Shiffrin (1968), we probably already have an adequate array of structural concepts: what is needed now is a model with control processes to direct information flow at the option of the $\mathrm{S}$.

\section{REFERENCES}

Atkinson, R. C.. Holmgren, J. E., \& Juola. J. F. Processing time as influenced by the number of elements in a visual display. Perception \& Psychophysics, 1969. 6. 321-326.

Atkinson. R. C, \& Shiffrin. R. II. Human memory: A proposed system and its control processes. In $K$. W. Spence and J. T. Spence (Eds.). The psychology of learning and motilation. New York: Academic Press. Pp. 89-195.

Bjork, E. L.. \& Estes. W. K. Detection and placement of redundant signal elements in tachistoscopic displays of letters. Perception \& Psy chophisics. 1971. 9. 439-442.

Briggs. G. E.. \& Blaha. J. Vemory retrieval and central comparison times in information processing. Journal of Experimental Psychology, 1969. 79. 395-402.

Burrows, D., \& Murdock, B. B.. Jr. Effects of extended practice on high-speed scanning. Journal of Experimental Psychology. 1969. 82. 231-237.

Collins. J. F.. \& Eriksen. C. H. The perception of multiple simultaneously presented forms as a function of foreal spacing. Perception \& Psychophysics. 1967. 2. 369-373.

Connor. J. M. Factors affecting parallel processing of visual display's. Lnpublished doctoral dissertation. University of Wisconsin. 1971

Donderi. D.. \& Case. B. Parallel visual processing: Constant same-different latency with two to fourteen shapes. Perception \& Psychophysics. 1970, 8. 373-375.

Donderi. D.. \& Zelnicker. D. Parallel processing in visual same-different decisions. Perception \& Psychophysics. 1969. 5. $197-200$.

Egeth. H. E.. Jonides. J.. \& Wall. S. Parallel processing of multielement displays. Cognitive Psychology. 1972. 3. 674-698.

Egeth. H. E.. Marcus. X.. \& Bevan. W. Target-set and response-set interaction: Implications for models of human information processing. Science. 1972. 176. 1447-1448.

Eriksen. C. W.. \& Spencer. T. Rate of information processing in visual perception: Some results and methodological considerations. Journal of Experimental Psychology Monograph. 1969. 79. No. 2

Estes. W. K.. \& Wessel. D. L. Reaction time in relation to display size and correctness of reponse in forced-choier risual ignal detectun. Perception \& Pathophysica 1966. 1.369-373

L ses. W. K. Interaction of vimal and background variable in 
visual processing. Perception \& Psychophysics, 1972, 12, 278-286.

Gardner, G. T. Spatial processing characteristics in the perception of brief visual arrays. Doctoral dissertation, University of Michigan, 1970. (Appears as Technical Report No. 23 from the Human Performance Center, University of Michigan.)

Gardner, G. T. Evidence for independent parallel channels in tachistoscopic perception. Cognitive Psychology, in press.

Gordon, I. E. Interaction between items in visual search. Journal of Experimental Psychology, 1968, 76, 348-355.

Holmgren, J. E. Response latency as an indicant of information processing in visual search tasks. Technical Report No. 153, Institute for Mathematical Studies in the Social Sciences, Stanford University, 1970.

Jonides, J., \& Gleitman, H. A conceptual category effect in visual search: $O$ as letter or as digit. Perception \& Psychophysics, 1972, 12, 457-460.

Neisser, U. Decision-time without reaction-time: Experiments in visual scanning. American Journal of Psychology, 1963, 76, 376-385.

Neisser, U. Cognitive psychology. New York Appleton-Century-Crofts, 1967.

Rumelhart, D. E. A multicomponent theory of the perception of briefly exposed displays. Journal of Mathematical Psychology, $1970,7,191-218$.

Sternberg, S. Scanning a persisting visual image versus a memorized list. Paper presented at the annual meeting of the Eastern Psychological Association, 1967.

Wolford, G. L., Wessel, D. L., \& Estes, W. K. Further evidence concerning scanning and sampling assumptions of visual detection models. Perception \& Psychophysics, 1968, 3, 439-444.

\section{NOTES}

1. For the purpose of this paper, we shall ignore the distinction between the yes-no variety of visual search (described above) and the forced-choice variety. In the forced-choice task, the $S$ must indicate which one of two target elements was present on each trial. This kind of task has been used by Estes and his colleagues, among others.

2. This slope was estimated from their Table 1, Block 1 (Days 1-3), data for "yes" responses with a memory load of 1.

3. An exception is the study by Briggs and Blaha (1969). Although target and nontarget sets were kept distinct throughout that experiment, the stimuli were random eight-sided polygons which are likely to be difficult to remember without extensive practice.

4. Even on an independent parallel channels model, mean RT might be expected to increase for a decision based upon an exhaustive (rather than a self-terminating) search; see the paper by Egeth et al (1972) for a fuller discussion of this point. Thus, the present discussion is based on the assumption that "presence" responses are based upon a self-terminating decision process.

(Received for publication November 13, 1972; revision received January 8, 1973.) 